\title{
Loneliness in the housewives in rising metro culture
}

\author{
Dr. Veena Yesikar ${ }^{1}$, Dr. Sanjay Dixit ${ }^{2}$, Dr. Sunil Kant Guleri ${ }^{3}$, \\ Dr. Geeta Shivram ${ }^{4}$ \\ 1 Associate Professor, Department of Community Medicine, MGM Medical College, Indore (Madhya Pradesh), India \\ 2 Professor, Department of Community Medicine, MGM Medical College, Indore (Madhya Pradesh), India \\ 3 Post graduate, Department of Community Medicine, MGM Medical College, Indore (Madhya Pradesh), India \\ 4 Demonstrator, Department of Community Medicine, MGM Medical College, Indore (Madhya Pradesh), India
}

\begin{abstract}
Loneliness is a subjective feeling expressed in different ways like feeling of isolation from the family, neighbors and or society. Housewives though working hard, not paid for their work, are left alone in the closed doors. Neither husbands nor anyone else is interested to share their feelings, ask problems and take care. Objective: to assess the presence of subjective feelings of loneliness or social isolation and factors responsible for loneliness in the housewives and its health consequences. Material and methods: A cross sectional study done in five randomly selected urban societies of Indore in a period of four months in 250 housewives selected by door to door survey. A pre designed, pre tested semi structured questionnaire derived from the revised ULCA scale of loneliness with biographical data and health measures was used. Statistical analysis: chi square test with $p<0.05$ as significant value Results: 48(19\%) housewives felt lack of closeness to family members, and 70(28\%) had feeling of insecurity. Lack to closeness with family members was significantly common in younger age $(29.5 \%, p=0.0016)$ and in housewives with higher qualification $(23 \%, p=0.018) .87(34.8 \%)$ of interviewed subjects had headache significantly associated with loneliness $(p=0.003)$ and $50 \%(127)$ had alteration in sleep $\&$ diet pattern. Conclusion: loneliness had lead to raise in psychosocial health problems among housewives which can be reduced by involving them in socio-cultural and recreational activities.
\end{abstract}

Key words: attitude, behavior, closeness, insecurity, loneliness.

\section{Introduction:}

Definition: The Dutch researcher Jenny de Jong-Gierveld defined loneliness as 'a situation experienced by the individual as one where there is an unpleasant or inadmissible lack of (quality of) certain relationships. This includes situations in which a number of existing relationships is smaller than considered desirable or admissible or situations where the intimacy one wishes for has not been realized. Thus, loneliness is seen to involve the manner in which a person experiences and evaluates his or her isolation and lack of communication with other people.' [1].

Effect of loneliness on health: Loneliness makes it harder for people to regulate themselves and leads to self-destructive habits, such as overeating or relying on alcohol. Loneliness weakens willpower and perseverance over time, so people who have been lonely for a while are more likely to indulge in behavior that damages their health. Lonely people are more likely to withdraw from engaging with others and less likely to seek emotional support, which makes them more isolated. Lonely people experience more difficulties sleeping, and sleep deprivation is known to have the same effects on metabolic, neural and hormonal regulation as ageing [2].

"Loneliness in the housewives in rising metro culture" meant for the various subjective feelings by housewives of being alone, isolated, during the hours when husbands are out for their offices and children in their school [3]. Problem occurs when this loneliness expresses itself in terms of various health related consequences. This may include frequent headaches, sleep disturbances (insomnia/excessive sleep), diet variation (anorexia/overeating) and irritable/depressive behavior of the housewives [4]. This problem is rising in modern metro culture.

Metro cities in India are the cities with population more than four million, and cities which are in race to get this status also follow their culture [5]. Metro culture involves "business" and "professionalism". People living here are extremely busy, working overtime to compete others. House wives are the biggest victim of this business! They find no companion to whom they can talk and share their feelings. Husbands and kids leaves early in the morning. Kids return from school and have coaching, extracurricular activities or spend their time in front of TV and computer games and internet. Studies have found newer technology like internet had huge impact on interpersonal communication [6]. Husbands return late with their files for homework and tired enough 
to get even a smile on their wives. This lifestyle had created a communication gap between husband, wives and even neighbors, which is responsible for loneliness among housewives.

It has been observed that women often suppress their need of autonomy, neglect their health and fail to equip with skills, competence and self-confidence [7]. Life style factors have a greater psychological impact than genetics, which increase longevity, delay illness and improve the quality of life. Health status, education, life style, family relationship and social class, are some of the major affecting factors in the lives of women [8]. Implications- women need to learn skills to know their inner spiritual self and in the company of that spiritual inner being, so that they will never feel lonely. Care should be provided to the housewife in the family, which is the basic mode or basic security umbrella. At the same time housewives should prepare themselves to cope up with the fast changing society and take initiative to get involved in community services. Attitude of the family towards the women need to be changed.

\section{Objective:}

- To assess the presence of subjective feelings of loneliness or social isolation in the housewives and its health consequences.

- To detect the extent of communication gap and factors responsible for loneliness.

- To improve the social life of the housewives by suggesting appropriate measures.

\section{Hypotheses:}

1. There will be positive relationship of loneliness with increase in age.

2. There will be positive relationship of loneliness with smaller family size.

3. There will be positive relationship of loneliness with private jobs of husbands.

4. There will be negative relationship of loneliness with increase in qualification of housewives.

\section{Materials and Methods:}

This was a cross sectional study done in five urban societies/ residential colonies of Indore selected by simple random sampling. 250 housewives were included in the study, 50 from each residential colony (Sample size was calculated with $95 \%$ confidence limit and $6 \%$ error level). Housewives living alone were the only included subjects and other working women/widows and those living in joint family were excluded. Door to door survey was done to identify and interview the subjects. A pre designed, pre tested semi structured questionnaire derived from the revised -UCLA (University Of California Los Angles) scale of loneliness with biographical data and possible health consequences (diet, sleep, stress, headache and depression) was administered.

Revised UCLA scale of loneliness (Russell et al, 1980) [9]: it includes 10 negatively worded and 10 positively worded items that have highest correlations with the questions that are related to loneliness. The revised loneliness scale has a high internal consistency with a coefficient alpha of 0.94[9].

The subjects were given possible suggestions to avoid loneliness and its ill effects. The data collected was fed into excel spread sheets and analyzed using statistical package for social sciences (SPSS). Chi square test of significance was applied where ever necessary and $\mathrm{p}$ value less than 0.05 was considered significant. The study was completed in four months (Sep 2012 to Jan 2012).

\section{Results:}

Among 250 housewives studied all were in the age group of 25-55 years. 165 (66\%) of them were older than 40 years and rest below 40 years. All were living in nuclear families (inclusion criteria) and 178 (71\%) of them had smaller families with four or less members in the family. $166(66 \%)$ of them were well qualified with graduate and above but still non working.

Table 1: subjective feelings of loneliness

\begin{tabular}{|l|l|l|l|l|l|l|l|}
\hline S. No: & Responses & \multicolumn{2}{|c|}{ Yes } & \multicolumn{2}{|c|}{ No } & \multicolumn{2}{l|}{ Total } \\
\hline & & $\mathbf{N}$ & $\mathbf{\%}$ & $\mathbf{N}$ & $\mathbf{\%}$ & $\mathbf{N}$ & $\%$ \\
\hline 1. & Lack of closeness to family members & 48 & 19 & 202 & 81 & 250 & 100 \\
\hline 2. & No support from husband & 40 & 16 & 210 & 84 & 250 & 100 \\
\hline 3. & Lack of respect and value in family & 44 & 17.5 & 206 & 82.5 & 250 & 100 \\
\hline
\end{tabular}

Among different subjective feelings the lack of closeness to family members was the most common.

Table 2 factors associated with feeling of lack of closeness to family members 
Loneliness in the housewives in rising metro culture

\begin{tabular}{|c|c|c|c|c|c|c|}
\hline & \multirow[t]{2}{*}{ Factors associated } & \multicolumn{2}{|c|}{ lack of closeness to family members } & \multirow[t]{2}{*}{ Total 250} & \multirow[t]{2}{*}{$X^{2}$ value } & \multirow[t]{2}{*}{ P value } \\
\hline & & Yes (48) & No $(202)$ & & & \\
\hline \multirow[t]{3}{*}{1.} & \multicolumn{4}{|l|}{ Age of the female } & \multirow[t]{3}{*}{8.657} & \multirow[t]{3}{*}{0.0016} \\
\hline & $\leq 40$ years & $25(29.5 \%)$ & $60(70.5 \%)$ & 85 & & \\
\hline & $\geq 40$ years & $23(14 \%)$ & $142 \quad(86 \%)$ & 165 & & \\
\hline \multirow[t]{3}{*}{2.} & \multicolumn{4}{|l|}{ No. of family members } & \multirow[t]{3}{*}{4.265} & \multirow[t]{3}{*}{0.0195} \\
\hline & 4 or less & $40(22.5)$ & $138(77.5 \%)$ & 178 & & \\
\hline & 5 or more & $8(11 \%)$ & $64(89 \%)$ & 72 & & \\
\hline \multirow[t]{3}{*}{3.} & Occupation of husbands & & & & \multirow[t]{3}{*}{$\mathbf{3 . 0 2 4}$} & \multirow[t]{3}{*}{0.0410} \\
\hline & Government employee & $15(14 \%)$ & $91 \quad(86 \%)$ & 106 & & \\
\hline & Private/ business/others & $33(23 \%)$ & $111(77 \%)$ & 144 & & \\
\hline \multirow[t]{3}{*}{4.} & Education of housewive & & & & \multirow[t]{3}{*}{4.340} & \multirow[t]{3}{*}{0.0186} \\
\hline & Graduate and above & $38(23 \%)$ & $128(87 \%)$ & 166 & & \\
\hline & $12^{\text {th }}$ pass and less & $10(12 \%)$ & $74(88 \%)$ & 84 & & \\
\hline
\end{tabular}

Author had to reject the null hypothesis that "there is no association of younger age, smaller family size, private job of husband and educational qualification on feeling of lack of closeness to family members" as on applying chi square, $p$ value came to be significant. The feeling was common in younger, higher qualified women with smaller families.

Table 3 Association of husband occupation with feeling of lack of respect and value

\begin{tabular}{|l|l|l|l|l|}
\hline \multirow{2}{*}{ Occupation of husbands } & \multicolumn{2}{|l|}{ Lack of respect and value } & \multirow{2}{*}{ Chi square P value } \\
\cline { 2 - 3 } & Yes & No & & \\
\hline Government employee & $15(14 \%)$ & $91(86 \%)$ & 106 & 0.1096 \\
\hline Private/ business/others & $29(20 \%)$ & $115(80 \%)$ & 144 & \multirow{2}{*}{ Not significant } \\
\hline Total & $44(17.5 \%)$ & $206(82.5 \%)$ & $\mathbf{2 5 0}$ & \\
\hline
\end{tabular}

Null hypothesis that occupation of husband (govt. or private) had no association with feeling of respect and value was found to be true. But feeling of closeness to family members was significantly common in wives of private workers/ businessmen.

Table 4 health consequences of loneliness

\begin{tabular}{|l|l|l|l|l|l|l|l|}
\hline \multirow{2}{*}{ S. no } & \multirow{2}{*}{ Consequences of loneliness } & \multicolumn{2}{|c|}{ Yes } & \multicolumn{2}{c|}{ No } & \multicolumn{2}{c|}{ Total } \\
\cline { 3 - 8 } & & No. & $\%$ & No. & $\%$ & No. & $\%$ \\
\hline 1. & Headache & 87 & 34.6 & 163 & 65.3 & 250 & 100 \\
\hline 2. & Sleep variations & 128 & 51.3 & 122 & 48.6 & 250 & 100 \\
\hline 3. & Diet variations & 131 & 48 & 119 & 52 & 250 & 100 \\
\hline 4. & $\begin{array}{l}\text { Behavioral changes } \\
\text { (irritability and depression) }\end{array}$ & 127 & 50.6 & 123 & 49.3 & 250 & 100 \\
\hline 5. & Feeling of Insecurity & 70 & 28 & 108 & 180 & 250 & 100 \\
\hline
\end{tabular}

Among the health consequences of loneliness almost half of the women had sleep/ diet variation and or behavior change. Headache and feeling of insecurity was also prevalent in more than $25 \%$ of women.

Table 5 change in sleep and dietary habits association with children worry among housewives

\begin{tabular}{|l|l|l|l|l|l|}
\hline $\begin{array}{l}\text { Worry for their children } \\
\text { wellbeing }\end{array}$ & Sleep variation present & Sleep variation absent & Total & $\mathbf{X}^{2}$ value & P value \\
\hline Yes & $91(55.8 \%)$ & $72(44.2 \%)$ & 163 & 4.016 & 0.0225 \\
\hline No & $37(42.5 \%)$ & $50(57.5 \%)$ & 87 & & \\
\hline Total & $\mathbf{1 2 8}(\mathbf{5 1 . 2 \%})$ & $\mathbf{1 2 2}(\mathbf{4 8 . 8 \% )}$ & $\mathbf{2 5 0}$ & & \\
\hline
\end{tabular}

The sleep and diet variation was significantly common in housewives who were worried all the time for their children regarding their academic performance, career, company, teenage behavior and over all wellbeing.

Lack of interaction with neighbors was significantly responsible $(\mathrm{p}=0.0398)$ for change in behavior among housewives. Similarly Feeling of insecurity was significantly $(\mathrm{p}=0.031)$ common in women not getting support from their husbands. Almost 50\% housewives spent their alone time watching TV. Only 30\% were involved in social / cultural activities, and $35 \%$ of all were doing regular exercise/ walking/ gym and yoga.

\section{Conclusion:}

There was considerable decrease in mutual communication between family members (husband and children) and the neighbors in metro cities like Indore. Social exclusion had been one of the important causes for 
feeling of loneliness among housewives. It was also an important cause of loneliness among elderly population [10]. There was lack of social gatherings, good understanding among family and neighbors. The feeling of loneliness was common in younger and well educated housewives. TABLE 2. It has also been found in the mental health foundation survey report of United kingdom which said that younger you are, the more likely you are to feel lonely. The report also said that loneliness is a problem of younger generation and more prevalent in females compared to males [11]. Housewives though well educated are not able to combat the loneliness effectively. TABLE 2. Lack of activities like yoga, physical exercises, gym, walking, and other hobbies in day to day life had raised the loneliness and its ill effects (headache, sleep and diet variation, irritable and or depressive behavior) on the health of housewives and family [11]. Housewives were over worried about their children's academic performance, behavior, company, career and well being. TABLE 5. This all lead to a marked variation in health of housewives found like sleep variations, diet variations and behavioral variations due to anxiety which may be due to increasing loneliness. TABLE 4.

To cope up with the rising metro culture, it is the need of time that housewives should make a positive attitude towards life, engage themselves in their hobbies, social gatherings, explore their talents, also they can opt for a part time or home based job. It is also necessary to improve the communication within family members and with the neighbors to create a friendly environment in the residential colonies. Developing satisfying personal relationship is an effective intervention to combat loneliness [12]. Health of the family starts with the housewives, so to make a healthy society, keep them happy and healthy.

\section{References:}

[1] De Jong Gierveld. July 1987. Developing and Testing a Model of Loneliness. Journal of Personality and Social Psychology Vol 53 (1)

[2] Cacioppo and Patrick (2008) Loneliness (as in note 5).

[3] Archana Singh and Nishi Misra.loneliness, depression and sociability in old age Ind Psychiatry J. 2009 Jan-Jun; 18(1): 51-55.

[4]. Green B. H, Copeland J. R, Dewey M. E, Shamra V, Saunders P. A, Davidson I. A, Sullivan C, McWilliam C. Risk factors for depression in elderly people: A prospective study. Acta Psychiatr Scand.1992;86(3):213-7.

[5] "India Stats : Million plus cities in India as per Census 2011". Press Information Bureau. 2011-10-31. Retrieved 2012-10-28.

[6] Rufus, A. (2008) Party of One: The Loners' Manifesto Berkeley, CA: Avalon Travel

[7] P. Joshi, L. Garon, And S. Lechasseur (1984) self-esteem and loneliness among unemployed women. Psychological Reports: Volume 54, Issue , pp. 903-906.

[8 Madhu Mathur. Depression and Life Style in Indian Ageing Women. Journal of the Indian Academy of Applied Psychology, January 2009, Vol. 35, No.1, 73-77.

[9] Russell D, Peplau L. A, Cutrona C. E. The revised UCLA Loneliness Scale: Concurrent \& discriminant validity evidence. Journal of Personality \& Social Psychology. 1980;39:472-480.

[10] Age Concern (July 2009) Social $\quad$ exclusion http://www.ageconcern.org.uk/AgeConcern/Documents/118_0609_Social_Exclusion_report.pdf

[11] Consumer experience 2009 research report OFCOM http/www.ofcom.org.uk/research/tce/ce09/research09.pdf

[12] Rook, K. S. (1984) promoting social bonding: strategies for helping the lonely and socially isolated American psychologist Vol. 38, No. 12, 1389-1407. 